\title{
Soroprevalência de anticorpos anti-Toxoplasma gondii em ovinos da raça Santa Inês na região da Grande Vitória, estado do Espírito Santo
}

\author{
Seroprevalence of Toxoplasma gondii antibodies in sheep Santa Ines \\ in Big Vitória, the state of Espirito Santo
}

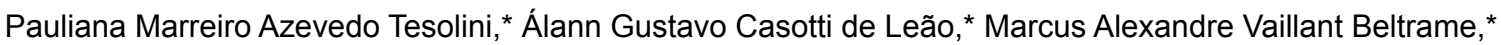 \\ Marcos Vinicius Gumieiro, ${ }^{*}$ Graziela Barioni*
}

\begin{abstract}
Resumo
A toxoplasmose tem como agente etiológico Toxoplasma gondii, possui distribuição mundial sendo de extrema importância médico-veterinária, uma vez que pode causar aborto e doenças congênitas em várias espécies de hospedeiros intermediários, além de ser considerada uma importante zoonose. O objetivo deste estudo foi pesquisar a soroprevalência de anticorpos antiToxoplasma gondii em ovinos da raça Santa Inês, criados em diferentes regiões dos municípios da Grande Vitória no estado do Espírito Santo (ES). Foram coletadas amostras de sangue de 236 ovinos criados em seis propriedades rurais dos municípios de Vila Velha, Guarapari, Serra e Cariacica. Os soros foram submetidos à reação de Hemaglutinação Indireta (HAI) para a detecção de anticorpos anti-T.gondii da classe IgG. A prevalência encontrada de soroconversão foi de $38,5 \%$. Em relação à faixa etária, foram encontrados $5,4 \%$ positivos nos animais jovens e 33,0\% nos adultos. A presença de gato, animais silvestres, o trânsito de animais e as condições de higiene das instalações influenciam diretamente na ocorrência da toxoplasmose em ovinos.
\end{abstract}

Palavras-chave: Toxoplasma gondii, toxoplasmose, ovinos, soroprevalência.

\begin{abstract}
Toxoplasma gondii, toxoplasmosis agent, possessing a cosmopolitan distribution is extremely important veterinary medication because it can cause miscarriages and congenital diseases in various species of intermediate hosts in addition to being considered one of the major zoonoses. The aim of this study was to investigate the seroprevalence of antibodies to Toxoplasma gondii in sheep of Santa Ines, created in different regions of the cities of Vitória in Espírito Santo (ES). Were collected blood samples from 236 sheep reared on six farms in the municipalities of Vila Velha, Guarapari, Sierra and Cariacica. Sera were submitted to the reaction of indirect hemagglutination (IHA) for detection of anti-T gondii IgG. The prevalence of seroconversion was $38.5 \%$. In terms of age group $5.4 \%$ were found positive in young animals and $33.0 \%$ in adults. The presence of cats, wild animals, the transit of animals and the hygiene conditions of premises directly influence the incidence of toxoplasmosis in sheep.
\end{abstract}

Keywords: Toxoplasma gondii, toxoplasmosis, sheep, seroprevalence.

\section{Introdução}

Toxoplasma gondii, agente etiológico da toxoplasmose, encontra-se distribuído mundialmente, é uma protozoonose de grande importância médico-veterinária e de saúde pública (Garcia et al., 1999).

Este parasito foi descrito pela primeira vez no ano de 1908, num roedor norte-africano (Fortes, 1997). Desde então trabalhos demonstram a importância econômica da infecção toxoplasmática em ovinos por ocasionar abortos, mumificação fetal, ocorrência de natimortalidade e nascimento de cordeiros fracos (Ogawa, 2003; Escopelli, 2004).
Os pequenos ruminantes assumem um importante papel na cadeia epidemiológica dessa doença, pois implica problemas de saúde pública, uma vez que a ingestão da carne crua ou malpassada contendo bradizoitos facilita a transmissão zoonótica deste protozoário, tendo assim relevância para a medicina veterinária e humana (Fortes, 1997; Uquhart et al., 1998; Pugh, 2004; Carneiro, 2006), tendo em vista que na linha da inspeção sanitária, os cistos não são visualizados (Moura et al., 2007). Garcia et al. (1999) relatou a prevalência de T. gondii nas espécies bovina, suína, ovina e equina oriundas de propriedades do município de Jaguapitã (PR) com elevada prevalência na espécie ovina, o que indica o alto risco da sua

\footnotetext{
* Médico-veterinário autônomo no Estado do Espírito Santo.

** Acadêmico do Curso de Medicina Veterinária da Universidade Federal do Espírito Santo CCA/UFES.

*** Professor do Curso de Medicina Veterinária do Centro Universitário Vila Velha - UVV.

${ }^{* * * *}$ Professora Adjunta do Departamento de Medicina Veterinária da Universidade Federal do Espírito Santo CCA/UFES. Autor para correspondência. E-mail: graziela.barioni@terra.com.br.
} 
carne como via de transmissão de forma infectante para o homem.

De acordo com Escopelli (2004) e Pugh (2004), a principal forma de contaminação para os pequenos ruminantes é pela ingestão de água e/ou alimentos contaminados com fezes de gato contendo oocistos. Urquhart et al. (1998) e Meireles et al. (2003) mostraram que existe infecção intrauterina, mas esta é rara.

Levantamentos sobre a distribuição mundial da toxoplasmose indicam que existe uma alta prevalência em algumas regiões, o que leva a um importante enfoque à doença. No Canadá, os valores encontrados foram de $65 \%$ em ovinos, e encontrada também uma alta prevalência nos animais silvestres. Uma pesquisa na Austrália demonstrou que $41 \%$ das criações de ovinos estavam infectadas (Blood e Radostits, 1991). No Reino Unido, a toxoplasmose ocupa o primeiro lugar, com $20 \%$ de perdas nos rebanhos (ocorrendo o aborto), com incidência anual de $2 \%$ da população nas ovelhas reprodutoras (Radotits et al., 2002).

A soroprevalência de anticorpos anti-Toxoplasma gondii em ovinos no Brasil são variáveis, e este comportamento deve-se principalmente ao teste sorológico utilizado, à região e idade dos animais estudados (Dubey, 1990). Por meio da reação de Sabin-Feldman (RSF), Larsson et al. (1980) encontraram 39,0\% de positividade em animais provenientes de Uruguaiana, RS, e abatidos em Bragança Paulista, SP.

Na região da Grande Porto Alegre (RS), Escopelli et al. (2004) estudou amostras de 250 animais utilizando diferentes técnicas como a imunofluorescência indireta (IFI) com resultados positivos em $15,2 \%$ das amostras sorológicas, e na técnica de hemaglutinação indireta $(\mathrm{HAI})$ encontrou $13,6 \%$.

Moura et al. (2007), ao pesquisarem anticorpos anti-Toxoplasma em 157 amostras de soros de ovinos oriundos do município de Guarapuava, PR, por meio de provas de imunofluorescência indireta (IFI), encontrou $7,0 \%$ de animais sororreagentes, sendo considerados positivos na diluição 1:64.

Em Pernambuco, Silva et al. (2003) observaram um percentual elevado, $35,3 \%$ dos animais positivos utilizando a prova de IFI, considerando amostras positivas a partir da diluição 1:16, o que pode ter justificado esse elevado percentual de animais positivos.

No Distrito Federal, Ueno (2005) observou nos rebanhos prevalência de $38,22 \%$, a análise foi realizada através da técnica de IFI, utilizando-se as diluições 1:64 como ponto de corte para T. gondii.

Em Minas Gerais, Carneiro (2006) encontrou uma prevalência de $31,0 \%$ através da técnica de ELISA, e 43,0\% utilizando a RIFI. Foi observada uma diferença estatística na prevalência da toxoplasmose quanto à faixa etária dos ovinos, o risco de animais infectados com idade superior a 36 meses foi maior quando comparados aos mais novos.

O objetivo deste estudo foi pesquisar a soroprevalência de anticorpos anti-Toxoplasma gondii em ovinos da raça Santa Inês, criados em diferentes regiões dos municípios da Grande Vitória no estado do Espírito Santo (ES).

\section{Material e métodos}

Foram testados 236 soros de ovinos, de seis propriedades rurais nos municípios que compõem a Grande Vitória: Vila Velha (15 animais), Cariacica (113 animais), Guarapari (70 animais) e Serra (38 animais). Sendo assim divididas: propriedade A e F localizadas no município de Guarapari; propriedades B e C no município de Cariacica; propriedade D no município da Serra e propriedade $E$ no município de Vila Velha.

O sangue foi coletado através da venopunção da veia jugular, usando tubos do tipo de coleta a vácuo sem anticoagulante com capacidade para $10 \mathrm{ml}$, devidamente identificados. Após a coleta, o sangue foi armazenado em isopor com gelo, e encaminhados para o Laboratório de Microbiologia do Centro Universitário Vila Velha (UVV) no Espírito Santo, onde foi realizada a centrifugação a 5.000 rpm por 10 minutos para obtenção do soro. O material foi acondicionado após a separação do coágulo, em microtubos $1,5 \mathrm{ml}$ e mantidos à temperatura de $-20^{\circ} \mathrm{C}$, até a realização dos testes laboratoriais.

Em todas as propriedades foi aplicado um questionário abordando dados sobre as propriedades, dentre os quais: fonte de água; manejo alimentar, sanitário e reprodutivo; instalações; tipo de exploração; presença de gatos; aspectos individuais de cada animal submetido à coleta de sangue (ex: idade e sexo).

Foi realizada no Laboratório de Microbiologia e Imunologia Veterinária do Centro Universitário Vila Velha (UVV), a técnica de hemaglutinação indireta (HAl) para a detecção de anticorpos (IgG) para Toxoplasma gondii, utilizando o Kit Imuno-HAI TOXOWAMA Diagnóstica ${ }^{\circledR}$, para determinação quantitativa e semiquantitativa de anticorpos anti-Toxoplasma gondii comercialmente disponível.

A técnica do $\mathrm{HAl}$ foi realizada na diluição 1:16 de acordo com a seguinte sequência: em tubos de ensaio foram colocados $150 \mu l$ do diluente, identificando cada tubo para cada amostra, adicionando $10 \mu \mathrm{l}$ de soro de ovino, homogeneizando-os. $\mathrm{Na}$ placa de microdiluição foram colocados $25 \mu$ lo soro controle positivo no poço 01 , soro controle negativo no poço 02 e nos poços seguintes a solução homogeneizada dos soros a serem testados. Em todos os poços forami adicionados $25 \mu$ l de solução de hemácias sensibilizadas (antígeno). A placa foi agitada manualmente por 3 minutos e incubada por 1-2 horas. A leitura foi realizada considerando-se resultados positivos para T. gondii as imagens em manto na placa e como negativos as imagens que formaram um botão.

\section{Resultados e discussão}

A Tabela 1 mostra a frequência de anticorpos para Toxoplasma gondii em soros de ovinos determinado pelo teste de hemaglutinação indireta (HAI). Do total de 236 amostras das seis propriedades (divididas em propriedade A, BCD, E e F) em diferentes localidade da Grande Vitória, todas tiveram animais com reações consideradas positivas na diluição 1:16 tendo o índice de positividade no total analisado de 38,5\%.

Os resultados encontrados através da sorologia por $\mathrm{HAl}$ em função da faixa etária dos animais (Tabela 2) foram semelhantes aos resultados encontrados por Ogawa (2003) e Carneiro (2006). Foi constatada maior ocorrência nos animais adultos, indicando que a infecção horizontal é a mais importante, o que sugere que animais adultos estiveram por mais tempo em contato com as possíveis vias de infecção do parasito, resultando em maior chance de se infectarem do que os mais jovens.

Foi escolhida a técnica de hemaglutinação indireta (HAI) para a detecção de anticorpos (lgG) para Toxoplasma gondii, devido 
Tabela 1: Resultados sorológicos ( $\mathrm{HAl}$ ) da classe IgG, na diluição 1:16, para T. gondii em ovinos oriundos de diferente regiões da Grande Vitória-ES, de acordo com o número de amostras coletadas em cada propriedade

\begin{tabular}{|c|c|c|c|c|c|}
\hline \multirow[t]{2}{*}{ Propriedades } & \multirow{2}{*}{$\begin{array}{l}\text { Número de } \\
\text { animais }\end{array}$} & \multicolumn{2}{|c|}{ Reagente } & \multicolumn{2}{|c|}{$\begin{array}{c}\text { Não } \\
\text { reagente }\end{array}$} \\
\hline & & Total & $\%$ & Total & $\%$ \\
\hline Propriedade A & 15 & 13 & 86,7 & 2 & 13,3 \\
\hline Propriedade B & 40 & 8 & 20,0 & 32 & 80,0 \\
\hline Propriedade C & 73 & 56 & 76,7 & 17 & 23,3 \\
\hline Propriedade D & 38 & 3 & 7,9 & 35 & 92,1 \\
\hline Propriedade $\mathrm{E}$ & 30 & 6 & 20,0 & 24 & 80,0 \\
\hline Propriedade F & 40 & 5 & 12,5 & 35 & 87,5 \\
\hline Total & 236 & 91 & $38,5 \%$ & 145 & $61,4 \%$ \\
\hline
\end{tabular}

Tabela 2: Resultados sorológicos (HAl-lgG) para anticorpos anti-T. gondii, de acordo com a idade dos ovinos, criados em diferentes regiões da Grande Vitória

\begin{tabular}{|c|c|c|c|c|c|c|}
\hline \multirow{2}{*}{ Idade } & \multicolumn{2}{|c|}{ Positivos } & \multicolumn{2}{|c|}{ Negativos } & \multicolumn{2}{|c|}{ Total } \\
\hline & Total & $\%$ & Total & $\%$ & Total & $\%$ \\
\hline Jovens * & 13 & 5,4 & 75 & 31,7 & 88 & 37,2 \\
\hline Adultos ** & 78 & 33,0 & 70 & 29,6 & 148 & 62,7 \\
\hline Total & 91 & 38,5 & 145 & 61,4 & 236 & 100 \\
\hline
\end{tabular}

* Menor que dois anos

** Maior que dois anos

a sua facilidade de realização, não exigindo equipamentos sofisticados, a boa sensibilidade, bem como ao seu razoável custo operacional, sendo um bom teste para triagem da toxoplasmose, assim como descrito por Escopelli (2004) e Costa (2007).

Pela avaliação da ficha epidemiológica que permitiu verificar que em todas as propriedades o tipo de criação foi semiextensivo; a alimentação dos animais em todas as propriedades era basicamente composta de pastagem, sendo que nas propriedades A (Guarapari, ES), B (Cariacica, ES), C (Cariacica, ES) e $E$ (Vila Velha, ES) os animais eram suplementados com ração. Pugh (2004) e Urquart (1998) apontaram problemas reprodutivos como o aborto, relacionado com a presença de gatos nas residências, pastos, instalações e depósitos de ração. Foi observada a presença de gatos em quase todas as propriedades, com exceção da propriedade $F$, o que pode justificar a baixa incidência da infecção nos animais desta propriedade.

A alta incidência de resultados positivos, $86,7 \%$ da propriedade A, pode estar diretamente ligada aos indícios da transmissão da toxoplasmose, tais como a presença de gatos nas instalações e dos pastos que se apresentavam pouco alagada, aumentado à distribuição de oocisto nas pastagens. Outro fator considerado foi a eliminação dos restos abortados, pois estes eram jogados no lixo, propiciando a contaminação dos ratos e dos gatos que os caçavam. A alta rotatividade de animais nesta propriedade, sem a realização de quarentena e de realização de exames, também propicia a entrada da doença nesta propriedade.

Na propriedade $B$, a higienização das instalações e cochos era feita de forma mais rigorosa, o que pode ter evitado o contato com os oocistos, apesar da presença de gatos, tendo acesso às instalações/ cocho/ pasto. A contaminação pode ter ocorrido pela existência de matas nas proximidades com uma variedade de animais silvestres, bem como pela alimentação com pastagem e/ ou capim picado contaminados, pois o mesmo era colocado no chão antes de ser picado, podendo ser contaminado com os oocistos.

Os achados não foram muito surpreendentes na propriedade $C$, devido a um grande número de fatores predisponentes presentes nesta propriedade. A presença de grande quantidade de gatos em contato direto com os ovinos (instalações/ cochos/ pasto), associada ao chão das instalações ser de areia, servindo de local para os gatos defecarem, tornando-se, assim, reservatório para os oocistos. Como neste local também ocorriam alguns partos, as ovelhas durante a limpeza dos borregos poderiam estar ingerindo areia contaminada. A fonte de água dos animais, adquirida em uma represa (água parada), poderia estar facilitando a transmissão para os ovinos. Blood e Radostits (1991) descreveram que a presença de matas nas proximidades da sede e pastos favorece a infecção da toxoplasmose pela existência de felinos silvestres. $O$ destino dos restos abortados também é um fator a ser ressaltado, uma vez que muitas vezes não eram vistos, ficando exposto no ambiente, facilitando a ingestão destes pelos felinos.

Alguns fatores devem ser apontados para explicar a baixa prevalência da toxoplasmose na propriedade D. Apesar da presença de gatos, os piquetes não eram próximos da sede (onde os gatos ficavam); a alimentação dos ovinos exclusivamente a pasto; a inexistência de matas nas proximidades da propriedade, e o fato de os gatos serem mais velhos e muito bem-alimentados pelos tratadores, portanto não tinham hábitos de caçar.

Os resultados encontrados na propriedade E, $20 \%$ de soropositividade (6/30), podem ter sido influenciados diretamente por grande parte dos animais testados terem sido adquiridos da propriedade $\mathrm{C}$, local de maior ocorrência de soropositivos. Ressalta-se que a presença de gatos na propriedade pode ter colaborado para o número de animais positivos na proprie-dade $\mathrm{E}$.

Na propriedade $F$, apesar de não haver a presença de gatos, não havia ocorrência de aborto nem a existência de matas nas proximidades, porém havia numa vila próxima à propriedade, a presença de gatos, o que pode ter levado à prevalência de $12,5 \%$ de animais positivos.

Quanto à frequência de T. gondii neste trabalho, encontraramse $38,5 \%$ de sororreagentes, utilizando a técnica da HAI. Resultados semelhantes foram encontrados por Larsson et al. (1980), Silva et al. (2003), Ueno (2005) e Carneiro (2006).

Foi descrita por Ogawa et al. (2003) sobre o estado do Paraná uma soroprevalência de $54,6 \%$ para T. gondii, superior à encontrada nesta pesquisa. A alta soroconversão foi explicada pelos autores, que consideram a presença de felinos em contado com os ovinos e seus fomentos, onde também foram encontrados problemas reprodutivos nos rebanhos. 
Resultado bem inferior aos registrados nessa pesquisa foi encontrado por Moura et al. (2007) no município de Guarapuava $(P R)$, encontrando $7 \%$. Esta baixa taxa de soropositividade pode ser explicada pela pouca idade dos animais, uma vez que o número maior de sororreagente geralmente é verificado em animais mais velhos.

Em todas as propriedades estudadas a criação de ovinos tem a finalidade de produção de carne, tendo a atenção da importância dos resultados deste trabalho uma vez que a carne de ovinos é uma importante fonte da infecção para o homem, sendo necessário estabelecer e conscientizar a população sobre essa zoonose. Alguns trabalhos relatam o isolamento de $\mathrm{T}$. gondii em tecidos comestíveis, como a carne crua ou malpassada de ovino. Sposito-Filha et al. (1992) isolaram cepas de toxoplasma a partir do diafragma de 100 ovinos e Bonametti et al. (1997) relataram 17 casos de toxoplasmose aguda sintomática, adquirida pela ingestão da carne crua de carneiro, $16(94,5 \%)$ pessoas apresentaram sinais.

Cuidados preventivos introduzidos no manejo do rebanho como higienização das instalações, incineração dos restos

\section{Referências}

BLOOD, D. C.; RADOSTITS, O. M. Clínica Veterinária. 7 ed. Rio de Janeiro: Guanabara Koogan, p.83-84, 1991.

BONAMETII, A. M.; PASSOS, J. do N.; SILVA, E. M. K.; BORTOLIERO, A. L. Surto de Toxoplasmose aguda transmitida através da carne crua de gado ovino. Revista da Sociedade Brasileira de Medicina Tropical, v. 30, n. 1, p. 21-25, 1997.

CARNEIRO, A. C. de A. V. Soroepidemiologia da toxoplasmose caprina e ovina no estado de Minas Gerais. Belo Horizonte, 2006. 116 p. Dissertação (Pós-Graduação) - Universidade Federal de Minas Gerais, 2006.

COSTA, T. L. da; SILVA, M. G. da; RODRIGUES, M. X.; BARABARESCO, A. A.; AVELINO, A. M. de. Diagnóstico Clínico e Laboratorial da Toxoplasmose. NewsLab. ed. 85. 2007.

DUBEY, J.P. Status of toxoplasmosis in sheep and goats in the United States. Journal of The American Veterinary Medical Association, v. 196, n. 2, p. 259-262, 1990.

ESCOPELLI, K. S. Avaliação sorológica de anticorpos da classe de IgG para Toxoplasma gondii em soros de ovinos da região da Grande Porto Alegre/RS, através das técnicas de Hemaglutinação Indireta (HAI) e Imunofluorescência Indireta (IFI). Porto Alegre, 2004. 94 p. Dissertação (Pós graduação) - Faculdade de Veterinária, Universidade Federal do Rio Grande do Sul, 2004.

FORTES, E.; Parasitologia veterinária. 3. ed. Local: Ícone, 1997.

GARCIA, J.L.; NAVARRO, I.T.; OGAWA, L.; OLIVEIRA, R.C. Soroprevalência do Toxoplasma gondii, em suínos, bovinos, ovinos e equinos, e sua correlação com humanos, felinos e caninos, oriundos de propriedades rurais do norte do ParanáBrasil. Ciência Rural, v. 29, n. 1, p. 91-97, 1999.

LARSSON, C. E.; JAMRA, L. M. F.; GUIMARÃES, E. C.; PATTOLI, D. B. G.; SILVA, H. L. L. Prevalência de toxoplasmose ovina determinada pela reação de Sabin-Feldman em animais de Uruguaiana, RS, Brasil. Revista Saúde Pública. São Paulo. v. 14, p. $582-588,1980$. abortados, estabelecendo o controle da infecção nesses animais principalmente em relação aos gatos domésticos, a fim de diminuir o risco de T. gondii nos rebanhos, visando reduzir as perdas econômicas e diminuir o risco de seres humanos adquirirem a doença pelo consumo de carne crua ou malpassada, demonstram a importância dessa doença.

\section{Conclusões}

A prevalência de anticorpos para Toxoplama gondii nos soros de ovinos da região da Grande Vitória analisados neste estudo foi de $38,5 \%$ pela técnica de Hemaglutinação Indireta.

Ficou evidente neste estudo que a presença de gatos, a existência matas nas proximidades das propriedades, a entrada de novos animais no rebanho sem o controle preventivo e o descuido com a higienização das instalações, estão relacionados com T. gondii na infecção nos ovinos.

Os ovinos abatidos na região da Grande Vitória podem ser considerados fontes de transmissão da toxoplasmose para humanos, quando a carne contaminada for consumida crua ou malcozida.

MEIRELES, L. R.; GALISTEU JR, A. J.; ANDRADE, H. F. Serological survey pf antibodies to Toxoplasma gondii in food animals from São Paulo, Brazil. Brazilian Journal of Veterinary Research and Animal Science, v. 40, n. 4, p. 267-271, 2003.

MOURA, A. B.de; OSAKI, S. C.; ZULPO, D. L.; MARANA, E. R. M. Ocorrência de anticorpos contra Toxoplasma gondii em suínos e ovinos abatidos no município de Guarapuava, PR, Brasil. Revista Brasileira de Parasitologia Veterinária, v. 16, n. 1, p. 54-56, 2007.

OGAWA, L.; NAVARRO, I. T.; FREIRE, R. L.; OLIVEIRA, R. C. de; VIDOTTO, O.; Ocorrência de anticorpos anti-Toxoplasma gondii em ovinos da região de Londrina, no Estado do Paraná. Semina: Ciências Agrárias, v. 24, n. 1, p. 57-62, 2003.

PUGH, D. G. Clínica de ovinos e caprinos. São Paulo.:Roca, 2004. RADOSTITS, O.M., GAY, C.C., BLOOD, D.C., HINCHCLIFF, K.W. Clínica veterinária: um tratado de doenças dos bovinos, ovinos, suínos, caprinos e equinos. 9. ed. Rio de Janeiro: Guanabara Koogan. 2002.

SILVA, A. V. da; CUNHA, E. L. P.; MEIRELES, L. R.; GOTTSCHALK, S.; MOTA, R. A.; LANGONI, H. Toxoplasmose em ovinos e caprinos: estudo soroepidemiológico em duas regiões do estado de Pernambuco, Brasil. Ciência Rural Santa Maria, v. 33, n. 1, p. 115-119, 2003.

SPOSITO-FILHA, E.; AMARAL, V. do; MACRUZ, R.; REBOUÇAS, M. M.; SANTOS, S. M.; DRUMOND, S. Toxoplasma gondii em ovinos: isolamento do parasito a partir de diafragmas de animais procedentes do estado do Rio Grande do Sul e abatidos em matadouros de São Paulo, para consumo humano. Revista Brasileira de Parasitologia Veterinária. v. 1, n. 2, p. 117-119. 1992.

UENO, T. E. H., Prevalência das infecções por Toxoplasma gondii e Neospora caninum em matrizes e reprodutores ovinos de rebanhos comerciais do Distrito Federal, Brasil. São Paulo, 2005. 104 p. Dissertação (Pós-Graduação) - Faculdade de Medicina Veterinária e Zootecnia da Universidade, 2005

URQUHART, G. M.; ARMOUR, J.; DUNCAN, J. L.; DUNN, A. M.; JENNINGS, F. W. Parasitologia Veterinária. 2. ed. Rio de Janeiro: Guanabara Koogan, 1998. 